\title{
PHYLOGENY OF NORMAL PERFORATE PALEOCENE PLANKTONIC FORAMINIFERA BASED ON WALL TEXTURE
}

OLSSON, Richard K., Department of Geological Sciences, Rutgers University, Piscataway, NJ 08855, USA; HEMLEBEN, Christoph, Institut und Museum für Geologie und Paläontologie der Universität Tübingen, D-7400 Tübingen, Germany.

The recovery of early Paleocene planktonic foraminifera from the end Cretaceous mass extinctions led to fundamental changes in the wall structure of the test, changes linked to the way in which the earliest Paleocene species were adapted to the water mass environment. These changes in wall structure, consequently, reflect biological activity. The great mass of planktonic foraminiferal species that came to occupy the Paleocene oceans are derived from two survivors (Hedbergella) which rapidly gave rise to distinct lineages. This group is characterized by having pore diameters of 2-7 $\mu \mathrm{m}$ (normal perforate) in contrast to an opportunistic earliest Danian group which has pore diameters of $<1 \mu \mathrm{m}$ (microperforate). Changes in the wall structure of the normal perforates were often quite dramatic and are similar, if not identical in some cases, to the wall structural and textural adaptations observed in living species of planktonic foraminifera. Since wall texture reflects the adaptive strategies exhibited in the biological activity of living species it provides a means for a biological classification and, in turn, it is an important guide to phylogenetic study. We regard this interrelationship as a unifying concept in the classification and phylogenetic study of Cenozoic planktonic foraminifera. The cancellate wall, which is a distinctive and diagnostic feature of the Cenozoic, is perhaps the most notable development in the Danian. One type of cancellate wall texture is characterized by having spines which are supported by terraced platelet growth of calcite crystals. This was an adaptation for more efficient food gathering (carnivory) and was widespread in species of Eoglobigerina, Parasubbotina, and Subbotina. Another type of cancellate wall texture that evolved in the Danian is seen in the nonspinose genus Praemurica which is comparable with the living species Neogloboquadrina dutertrei. The cancellate pattern is due to the formation of subparallel low ridges which are connected by short ridges. It is a very common structure in Paleogene and Neogene planktonic foraminifera. This type of wall texture occurs in the Paleocene genera Igorina and Praemurica.

Two types of noncancellate wall texture are characterized by a smooth nonspinose wall with more or less scattered pustules and a heavily pustulose wall. The smooth wall type is seen in species of Globanomalina. The heavily pustulose (muricate) wall texture occurs in the genera Acarinina and Morozovella. The test wall is characterized by large very coarse pustules which may cover the entire test or be concentrated on the umbilical shoulders or be confined to the periphery of the test enforcing the keel. The pustules grow on a smooth surface which points to the origin of these genera from Globanomalina which is contrary to the hypothesis that these genera are derived from the praemuricate species, $P$. uncinata. 